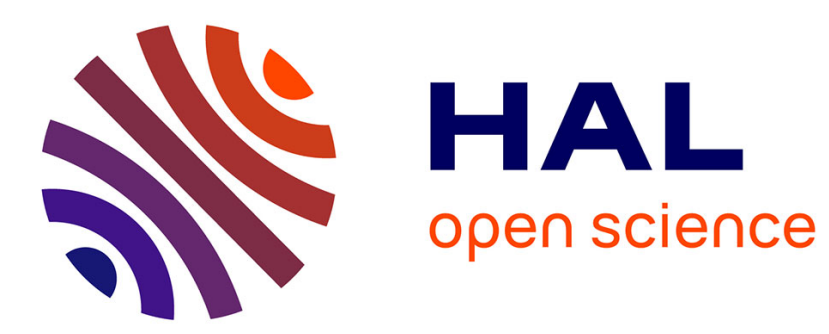

\title{
La damnatio memoriae dans les oeuvres historiques de Suétone et de Tacite
}

Céline de Jonquières, Virginie Hollard

\section{To cite this version:}

Céline de Jonquières, Virginie Hollard. La damnatio memoriae dans les oeuvres historiques de Suétone et de Tacite. Cahiers du Centre Gustave Glotz, 2008, 19 (1), pp.145-163. 10.3406/ccgg.2008.1673 . hal-02469101

\section{HAL Id: hal-02469101 \\ https://hal.science/hal-02469101}

Submitted on 6 Feb 2020

HAL is a multi-disciplinary open access archive for the deposit and dissemination of scientific research documents, whether they are published or not. The documents may come from teaching and research institutions in France or abroad, or from public or private research centers.
L'archive ouverte pluridisciplinaire HAL, est destinée au dépôt et à la diffusion de documents scientifiques de niveau recherche, publiés ou non, émanant des établissements d'enseignement et de recherche français ou étrangers, des laboratoires publics ou privés. 


\section{LA DAMNATIO MEMORIAE DANS LES CEUVRES HISTORIQUES DE SUÉTONE ET DE TACITE}

À Rome, il y a condamnation de mémoire lorsque des mesures prises à l'encontre du défunt empêchent ses proches et l'ensemble de la cité de l'honorer par des funérailles et de vivre dans son souvenir. Cette pratique existait déjà à l'époque républicaine sous la forme d'une décision sénatoriale dans le cadre d'un procès. M. Bats, à travers l'étude des sources littéraires, a pu démontrer que les premières victimes identifiées de la damnatio memoriae ont été les Gracques ${ }^{1}$. Leurs corps subirent des outrages et furent jetés dans le Tibre par les partisans du Sénat ${ }^{2}$. Cette privation de sépulture constitua la première étape d'une condamnation de mémoire puisqu'elle interdit aux descendants de rendre un culte à leurs ancêtres lors des fêtes qui leur furent consacrées. Un deuxième exemple est le cas d'Antoine qui est déclaré hostis publicus par un vote du Sénat ${ }^{3}$ en 44 av. J.-C. avant de retrouver son statut. Sa condamnation apparut véritablement après la victoire d'Actium ${ }^{4}$ lorsque le Sénat vota la destruction de ses statues, l'annulation de ses honneurs ainsi que l'interdiction faite à ses descendants de prendre le praenomen de Marcus ${ }^{5}$. De plus, nous savons que son nom fut martelé sur certains documents publics ${ }^{6}$ et que son dies natalis fut considéré comme un dies uitiosus ${ }^{7}$. Une lecture des Res Gestae diui Augusti confirme cette damnatio puisque Marc-Antoine n'y est

${ }^{1}$ E. Badian, «Tiberius Gracchus and the Beginning of the Roman Revolution ", $A N R W$, I, 1, New York-Berlin, 1972, p. 668-731. La condamnation de Caius Gracchus fut justifiée par l'utilisation du Senatus Consultum Ultimum: J. Von Ungern-Sternberg von Pürkel, Untersuchungen zum Spätrepublikanischen Notstandrecht, Senatus Consultum ultimum und hostisErklärung, Munich, 1970; M. Bats, "Mort violente et damnatio memoriae sous les Sévères dans les sources littéraires ", Cahiers Glotz, 14, 2003, p. 281-298.

${ }^{2}$ Liu., Per., 58, 7 ; Val.-Max., 4, 7, 2; 6, 3, 1d; Plut., Tib. Grac., 20, 3-4 ; Ap., B.C., 1, 2, 16 ; Epit., 64, 8; Oro., 5, 9, 3.

${ }^{3}$ Ap., B.C., 4, 6, 45; Plut., Ant., 17, 1.

${ }^{4}$ Plut., Cic., 49, 6; Ant., 86, 9; Dio, 51, 19, 135 ; P.W. Harsh, «The role of the ghost of Cicero in the damnation of Antony ", $C W, 47,1954$, p. 97-103; C. L. Babcock, " Dio and Plutarch on the damnatio of Antony ", CPh, 57, 1962, p. 30-32.

5 Plut., Cic., 49, 6.

${ }^{6}$ CIL, I ${ }^{2}$, p. 64 (Fasti Colotiani), 31 septembre 38: [M. A]emilius [[M. Antonius]] Imp(erator) Caesar.

7 Suet., Claud., 11, 6: Ne Marcum quidem Antonium inhonoratum ac sine grata mentione transmisit, testatus quondam per edictum, tanta impensius patere se ut natalem patris Drusi celebrarent, quod idem esset et aui sui Antonii; H. Bengtson, Marcus Antoninus : Triumvir und Herscher des Orients, Munich, 1977, p. 286-299.

Cahiers Glotz, XIX, 2008, p. 00-00 
jamais cité ${ }^{8}$. De cette pratique républicaine émergent deux caractéristiques ayant abouti à la mise en place de ce qui constitua, à l'époque impériale, la réalité de la damnatio memoriae réservée aux empereurs: le fait, tout d'abord, qu'il s'agisse d'une décision sénatoriale (et pas seulement dans un contexte judiciaire), le fait ensuite que les mesures prises interviennent dans l'espace public et ne concernent pas uniquement le deuil familial. Au tout début de l'Empire, les particuliers qui subirent des condamnations de mémoire le furent à la suite de procès pour crimen maiestatis ${ }^{9}$ et perduellio ${ }^{10}$. Seuls les empereurs furent victimes de l'abolitio memoriae consécutif à un vote législatif du Sénat. Mais, après le règne de Tibère, l'usage réservé jusque-là aux empereurs s'étendit aux particuliers. Les patres furent les seuls à pouvoir porter atteinte à la mémoire de quelqu'un, que ce soit dans un contexte judiciaire ou législatif. Nous retrouvons à travers la lecture de Suétone et de Tacite la spécificité des règnes d'Auguste et de Tibère: celle d'une période de mise en place de pratiques qui deviennent par la suite un usage, s'insérant ainsi dans le mos. L'étude des œuvres historiques de Suétone et de Tacite, deux auteurs du $\mathrm{II}^{\mathrm{e}}$ siècle ayant connu l'abolitio memoriae de Domitien, nous permet de dresser un tableau le plus complet possible de ce que furent les différents cas de damnatio memoriae au Ir siècle. Nous nous intéresserons à l'évolution de cette procédure, puis aux réactions populaires, enfin aux moyens de rétablir la mémoire ou d'anticiper une condamnation.

\section{L'ÉVOLUTION DE LA PROCÉDURE D'ABOLITIO MEMORIAE}

\section{Les premières atteintes de la mémoire}

Dans la continuité des pratiques républicaines, les atteintes à la mémoire sont décidées par le Sénat, dans le cas de procès intentés contre des particuliers. Les décisions prises concernent essentiellement la personne condamnée et son image : atteinte au cadavre, destruction des statues. De telles décisions sont privées en ce qu'elles n'ont pas de répercussions sur des pratiques collectives. Ces condamnations n'apparaissent dans les sources que sous le règne de Tibère. Les différentes mesures juridiques prises seront la base des sanctions décidées par le Sénat pour abolir la mémoire d'un mauvais princeps à sa mort ${ }^{11}$.

${ }^{8}$ M.V. Ronnick, «Res gestae 25 : damnatio memoriae as a strategy of rhetoric », Maia, 49, 1997 , p. 381-384.

${ }^{9}$ H. C. Brecht, «Perduellio und crimen maiestatis », ZRG, 59, 1944, p. 354-359; C. W. Chilton, "The Roman law of treason under the Early Principate ", JRS, 45, 1955, p. 73-81; R. J.A. Bauman, A Study of the Crimen Maiestatis Imminutae in the Roman Republic and Augustan Principate, Johannesburg, 1963; M. A. Levi, « Maiestas e crimen maiestatis ", PP, 24, 1969, p. 81-96; R. J. A. Bauman, The Crimen Maiestatis in the Roman Republic and Augustan Principate, Johannesburg, 1970; A. Magdelain, "Remarques sur la Perduellio », Historia, 22, 1973, p. 405-422.

10 A. R. Hands, "The timing of suicide ", $P A C A, 5,1962$, p. 27-31; A. Magdelain, "Perduellio ", cit. supra.

${ }^{11}$ Les principales condamnations ont été analysées dans le cadre des conspirations par I. Cogitore, La légitimité dynastique d'Auguste à Néron à l'épreuve des conspirations, Rome, 2002, ou 
Libo Drusus ${ }^{12}$

Dans l'œuvre de Tacite, il s'agit du premier procès pour crimen maiestatis sous le règne de Tibère ${ }^{13}$. L'auteur décrit cette affaire dans le livre II des Annales en évoquant la manière dont l'accusation contre Libo Drusus se met en place ${ }^{14}$. Il précise les sanctions qui furent prises à son encontre par le Sénat alors qu'il s'était suicidé avant la fin de son procès. Les sénateurs décidèrent que ses imagines ne pourraient pas figurer dans les cortèges funéraires de ses descendants, et qu'aucun membre de la gens des Scribonii ne pourrait prendre le surnom de Drusus ${ }^{15}$. Ces deux décisions, qui reprennent des sanctions républicaines, furent votées afin d'éviter qu'un membre de la famille de Libo Drusus ne puisse revendiquer un lien avec la famille impériale ${ }^{16}$. Ses biens furent partagés entre les accusateurs ${ }^{17}$. Pour Tacite il s'agit de souligner le début du rôle néfaste des délateurs ${ }^{18}$. Pour la première fois, la répression d'une conspiration fut célébrée dans les Fastes ${ }^{19}$ et des jours de supplications furent décrétés ${ }^{20}$. Ces décisions permettaient au régime de faire de Libo Drusus un exemple, afin d'éviter toute autre tentative de conspiration.

\section{Cn. Pison père}

La procédure d'abolitio memoriae la plus connue pour un particulier est celle de Cn. Pison père, grâce à la découverte du senatus consultum relatant les

à travers l'étude du senatus consultum de Cn. Pisone Patre: A. Caballos, W. Eck, F. Fernández, El senadoconsulto de Cneo Pisone Padre, Séville, 1996; W. Eck, A. Caballos, F. Fernández, Das Senatus Consultum de Cn. Pisone Patre, Munich, 1996; Les condamnations des membres de la domus Augusta sont principalement étudiées dans les biographies de Tibère ou de Séjan: E. Meise, Untersuchungen zur Geschichte der Julisch-Claudischen Dynastie, Munich, 1969, p. 49-92 et p. 237244 ; D. Hennig, L. Aelius Seianus. Untersuchungen zur Regierung des Tiberius, Munich, 1975, p. 86101 ; B. Levick, Tiberius the Politician, Londres, 1976, p. 201-225.

${ }^{12}$ RE, II, A1, 1921, s.u. Libo, col. 885-887, n. 22 (M. Fluss); PIR 2 , S 268.

${ }^{13}$ V. Strazzula, "Il processo di Libone Druso ", RSA, 12, 1908, p. 62-73; 13, 1909, p. $243-$ 258; A. Passerini, «Per la storia dell'imperatore Tiberio. II : il processo di Libone Druso », dans Studi giuridici in memoria di P. Ciapessoni, Pavie, 1948, p. 195-233; M. L. Paladini, "L'imperatore Tiberio e i primi processi politici del suo regno ", RBPh, 46, 1968, p. 25-41; D. C. A. Shotter, "The Trial of M. Scribonius Libo Drusus », Historia, 21, 1972, p. 88-98; I. Cogitore, La légitimité dynastique, cit. supra, p. 181-191.

${ }^{14}$ Tac., Ann., 2, 27-32; Suet., Tib., 25, 1 : L. Scribonius Libo uir nobilis res nouas clam moliebatur; O. Licandro, In magistratu damnari: ricerche sulla responsabilità dei magistrati romani durante l'esercizione delle fuzioni, Turin, 1999, p. 373-376.

${ }^{15}$ Tac., Ann., 2, 32, 2-3: Tunc Cotta Messalinus, ne imago Libonis exequias posterorum comitaretur, censuit, Cn. Lentulus, ne quis Scribonius cognomentum Drusi adsumeret.

${ }^{16}$ J. Scheid, «Scribonia Caesaris et les Julio-Claudiens. Problèmes de vocabulaire de parenté ", MEFRA, 87, 1975, p. 349-375.

${ }^{17}$ Tac., Ann., 2, 32, 1: Bona inter accusatores diuiduntur.

18 Tac., Ann., 2, 27, 1: Eius negotii initium, ordinum, finem curatius disseram, quia tum primum reperta sunt quae per tot annos rem publicam exedere; 32, 2: ut sciretur uetus id in re publica malum; S. H. Rutledge, Imperial Inquisitions. Prosecutors and Informants from Tiberius to Domitian, Londres, 2001, p. 158-161; Y. Rivière, Les délateurs sous l'Empire romain, Rome, 2002, p. 88-91.

${ }^{19}$ I. Ital., XII, 2, p. 193 : Fast. Amit., nefaria consilia quae de salute Ti(beri) Caes(aris) liberorumq(ue) e(ius) et aliorum principum ciuitatis deq(ue) r(e) p(ublica) initia ab M. Libone erant.

${ }^{20}$ Tac., Ann., 2, 32, 2 : Supplicationum dies Pomponii Flacci sententia constituti, et dona Ioui, Marti, Concordiae, utque iduum Septembrium dies, quo se Libo interfecerat, dies festus haberetur. 
mesures prises à son encontre ${ }^{21}$. Après la mort de Germanicus, Cn. Pison père fut suspecté d'avoir empoisonné le co-régent. En 20, lors de son retour à Rome, il fut convoqué au Sénat pour répondre de ses actes ${ }^{22}$. Tibère ouvrit la séance en condamnant toute décision excessive qui pourrait être prise ${ }^{23}$. La victime prévenue se donna la mort ${ }^{24}$, mais son procès continua ${ }^{25}$ après que Tibère eut acquitté son fils aîné ${ }^{26}$. Les sénateurs décidèrent d'effacer le nom de $\mathrm{Cn}$. Pison des $\mathrm{Fasti}^{27}$, de lui confisquer une partie de ses biens ${ }^{28}$, d'empêcher à ses descendants de porter le prénom de Cnaeus ${ }^{29}$, de supprimer ses statues ${ }^{30}$ et d'interdire que son imago n'apparaisse dans les funérailles de ses descendants ${ }^{31}$. Ces sanctions furent prises par le Sénat sous la pression de la plèbe qui manifestait au dehors. La confrontation des deux sources, épigraphique et littéraire, nous permet de comprendre les sanctions qui étaient les plus significatives pour Tacite. Ce dernier indique seulement la décision d'érasure du nom de Cn. Pison sur les Fastes et le fait qu'aucun de ses descendants ne pourra porter le prénom de Cnaeus. Plus que les destructions de statues, ces décisions sont durables et donc plus efficaces en ce qui concerne la condamnation de la mémoire.

\section{Séjan}

Un autre cas évoqué dans les sources est celui de Séjan ${ }^{32}$, préfet du prétoire de Tibère. Ce dernier fut accusé par l'empereur de mener une conspiration contre lui. Les motivations de ce complot sont assez vagues ${ }^{33}$.

${ }^{21}$ Senatus consultum de Cn. Pisone patre, abrégé en SCPP.

${ }^{22}$ Tac., Ann., 3, 10, 1 : Postera die Fulcinius Trio Pisonem apud consules postulauit; W. Eck, " Mord im Kaiserhaus? Ein politischer Prozess im Rom des Jahres 20 n. Chr. ", Jahrbuch des Historischen Kollegs, 1996, p. 99-132; J. Bodel, "Punishing Piso », AJPh, 120, 1999, p. 43-63.

${ }^{23}$ Tac. Ann., 3, 12, 1 : Die senatus Caesar orationem habuit meditato temperamento; 4 : nam quo pertinuit nudare corpus et contrectandum unlgi oculis permittere differrique etiam per externos tamquam ueneno interceptus esset, si incerta adhuc ista et scrutanda sunt? Dans ce passage, Tacite nous indique que la peine de mort entraîne forcément une dégradation du cadavre et son exposition aux Gémonies; C. Damon, «Relatio vs. Oratio:Tacitus, Ann., 3, 12 and the Senatus Consultum de Cn. Pisone Patre ", CQ, 49, 1999, p. 336-338.

${ }^{24}$ SCPP, 1. 6-7; 1. 71-72; Tac., Ann., 3, 15, 3: et, coepta luce, perfosso ingulo, iacente humi gladio, repertus est.

${ }_{25}$ SCPP, 1. 18-19; Tac., Ann., 3, 17, 3: Biduum super hac imagine cognitionis absumptum.

${ }^{26}$ SCPP, 1. 8;1.100-102;Tac., Ann., 3, 17, 1: Post quae Tiberius adulescentem crimine ciuilis belli purgauit, patris quippe iussa nec potuisse filium detrectare.

${ }^{27}$ Cette décision n'apparaît pas dans le SCPP. Dans le texte, il est seulement fait mention de l'inscription honorifique de la statue de Germanicus: 1. 83-84. Tacite indique que Tibère refusa que cette mesure soit prise:Tac., Ann., 3, 18, 1.

${ }^{28}$ SCPP, 1. 84-85.

${ }^{29}$ Tac., Ann., 3, 17, 4: Primus sententiam rogatus, Aurelius Cotta, consul (nam, referente Caesare, magistratus eo etiam munere fungebantur) nomen Pisoni radendum fastis censuit, partem bonorum publicandam, pars ut Cn. Pisoni filio concederetur isque praenomen mutaret.

${ }^{30}$ SCPP, $1.75-80 ; 1.83-84$.

31 SCPP, 1. 80-82.

${ }^{32}$ RE, I, 1984, s.u. Aelius, col. 529-531, n. 133; PIR ${ }^{2}$, A 255 ; D. Hennig, L. Aelius Seianus. Untersuchungen zur Regierung des Tiberius, Munich, 1975.

${ }^{33}$ I. Cogitore, La légitimité dynastique, cit. supra, p. 211-228. 
Malheureusement, les œuvres de Tacite et de Suétone apportent peu d'éléments sur l'événement et sur la condamnation de Séjan ${ }^{34}$. Par un discours de M. Terentius ${ }^{35}$, Tacite nous apprend que Séjan fut condamné pour atteinte à l'État et tentative de meurtre sur la personne de l'empereur ${ }^{36}$. À la suite de la lecture d'une lettre de Tibère au Sénat, Séjan fut arrêté. Les sénateurs décidèrent qu'il devait mourir empoisonné. Une fois la sentence exécutée, son corps resta exposé à la haine du peuple avant d'être jeté dans le Tibre ${ }^{37}$. Tacite ne nous apporte que des informations sur le sort de ses descendants. Son fils aîné et sa fille furent condamnés à mort ${ }^{38}$, son fils cadet fut adopté par un Capito. Sa fille fut victime d'un double châtiment. Le bourreau pour pouvoir la mettre à mort dut la violer ${ }^{39}$. Face à ce spectacle atroce, leur mère, qui avait été épargnée, se suicida ${ }^{40}$. La décision de la condamnation à mort est prise par le Sénat. Il n'est pas fait mention d'un vote. Cependant, en nous référant à la manière dont $\mathrm{Cn}$. Pison fut condamné, il dut y avoir le vote d'un senatus consultum. Encore une fois, il s'agissait d'empêcher que la mémoire de Séjan puisse être honorée par ses descendants.

Les deux Julies

Exilées par Auguste, elles sont restées sans sépulture digne de ce nom. C'est par ce traitement infamant qu'il y a une atteinte à leur mémoire. Le premier princeps réaffirme dans son testament que, même dans la mort, elles sont exclues de la domus Augusta. Leurs cendres ne peuvent donc pas être déposées dans le mausolée dynastique ${ }^{41}$.

${ }^{34}$ Nous savons par l'épigraphie et d'autres sources littéraires qu'il fut déclaré hostis publicus et condamné, et que cette décision bénéficia d'une large diffusion: CIL, XI, 4170 (ILS, 157), Interamna: Saluti perpetuae Augustae / libertatique publicae / populi Romani / Genio municipi anno post / Interamnam conditam / DCCIIII ad Cn. Domitium / Ahenobarbum [[M. Furium / Camillum Scribonianum ]] cos. / Pronidentia Ti. Caesaris augusti nati ad aeternitatem / Romani nominis, sublato hoste perniciosissimo p. R., / Faustus Titius Liberalis VIuir Aug. iter. / p(ecunia) s(ua) f(aciundum) c(urauit); I. Ital., XIII, 1, p. 187 ; Fast. Ost., 31 apr. J.-C.: VIII K(alendas) Nou(embres) Strabro [Seiani] / f(ilius) strang(ulatus); VII K(alendas) No[u(embres) Apicata] / Seiani se occidi[t ---] ; Seiani se occid(it) / Dec(imus) Capito Aelian[nus et] / Iunilla Seianif(ilia) [in Gem(oniis)] / iacuerunt; Iuv., 10, 86; Dio, 58, 10, 3-5; 11, 5-6.

${ }^{35}$ RE,V, A1, 1934, s.u. Terentius, col. 597, n. 28 (A. Stein); PIR ${ }^{2}, \mathrm{~T} 48$.

${ }^{36}$ Tac., Ann., 6, 8, 6: Insidiae in rem publicam, consilia caedis aduersus imperatorem puniantur.

37 Dio, 58, 10, 3-5; 11, 5-6. Séjan n'était pas particulièrement aimé de la plèbe. R. Syme, "Seianus on the Aventine ", Hermes, 84, 1956, p. 257-266, indique qu'il avait une relation démagogique avec cette dernière. Son élection au consulat sur l'Aventin est toujours problématique: M. Pani, "Seiano e la nobilitas. I rapporti con Asinio Gallo ", RFIC, 107, 1979, p. 142-156; Z. Yavetz, "Seianus and the plebs. A Note », Chiron, 28, 1998, p. 187-191.

38 Tac., Ann., 5, 9, 1 : Placitum posthac ut in reliquos Seiani liberos aduerteretur.

${ }^{39}$ Tac., Ann., 5, 9, 2: Tradunt temporise ius auctores, quia triumuirali supplicio adfici uirginem inauditum habebatur, a carnifice laqueum iuxta compressam; exim, oblisis faucibus, id aetatis corpora in Gemonias abiecta; Suet., Tib., 61, 14 : Immaturae puellae, quia more tradito nefas esset uirgines strangulari, uitiatae prius a carnifice. Suétone mentionne cette anecdote dans un long paragraphe où il dénonce les actes de barbarie commis sous le règne de Tibère.

${ }^{40}$ I. Ital., XIII, 1, p. 187 : Fast. Ost. : pour l'année 31, cf. supra n. 34 ; Dio, 58, 11, 5-6.

${ }^{41}$ Suet., Aug., 101, 5 ; PIR $^{2}$, I 634-5; RE, X, 1, 1918, col. 896 et suiv., n ${ }^{\circ} 550$ (K. Fitzler). Cf. H. von Hesberg, S. Panciera, Das Mausoleum des Augustus, Munich, 1994, p. 81-82. 
Le tournant au $I^{\text {er }}$ siècle: les empereurs damnati memoriae

Le règne de Tibère apparaît dans les sources comme le moment où la procédure de damnatio memoriae se met en place. Ses deux caractéristiques principales (décision sénatoriale en dehors du cadre d'un procès et application des mesures dans l'espace public) ne valent que pour les empereurs et leur entourage immédiat.

À la différence des cas précédemment examinés, la famille de Germanicus (sa femme et ses descendants) subit des atteintes à la mémoire, non à la suite d'un procès mais par la simple volonté de Tibère. Ils furent pourchassés par le princeps qui voyait en eux des opposants potentiels ${ }^{42}$. À la suite d'une lettre de Tibère adressée au Sénat, Drusus et Néron ${ }^{43}$ furent déclarés hostes publici ${ }^{44}$. Tacite indique que, dans cette missive, Tibère dénonçait les agissements de Néron et d'Agrippine ${ }^{45}$. Drusus fut emprisonné dans les sous-sols du Palatin et Néron fut exilé sur une île tout comme sa mère ${ }^{46}$. Ces décisions furent prises par le Sénat, c'est-à-dire qu'il y eut certainement le vote d'un sénatusconsulte. À la mort de sa belle-fille, Tibère déclara que son jour d'anniversaire était un dies nefastus ${ }^{47}$. De plus, il décida qu'il fallait consacrer des offrandes à Jupiter le jour de sa mort: le 18 octobre (le même que celui de Séjan) ${ }^{48}$. Il aurait souhaité la faire condamner et jeter son corps du haut des Gémonies ${ }^{49}$. Un condamné dont le corps avait été exposé aux Gémonies ne pouvait pas bénéficier des derniers honneurs et recevoir une sépulture ${ }^{50}$. Sa famille ne pouvait lui rendre hommage lors des cérémonies consacrées aux morts et sa

42 D. C. A. Shotter, "Agrippina the Elder: a woman in a man's world ", Historia, 49, 2000, p. 341-357.

${ }^{43} P I R^{2}$, I 220 ; RE, X, 1, 1918, s.u. Iulius, col. 434-435, n. 137 (V. Gardthausen); PIR ${ }^{2}$, I 636 ; RE, X, 1, 1918, s.u. Iulius, col. 473-475, n. 146 (V. Gardthausen).

${ }^{44}$ Suet., Tib., 54, 3: Atque ex eo patefacta interiore animi sui nota omnium criminationibus obnoxios reddidit uariaque fraude inductos, ut et concitarentur ad connicia et concitati proderentur, accusauit per litteras amarissime congestis etiam probris et iudicatos hostis fame necauit Neronem in insula Pontia, Drusum in ima parte Palatii.

${ }^{45}$ Tac., Ann., 5, 3, 1: tunc, uelut frenis exsoluti, proruperunt missaeque in Agrippinam ac Neronem litterae. Les informations fournies par les deux auteurs divergent.

${ }^{46}$ PIR, V, $463 ;$ FOS, n 812.

${ }^{47}$ Suet., Tib., 53, 5: sed et perseuerantem atque ita absumptam criminosissime insectatus, cum diem quoque natalem eius inter nefastos referendum suasisset; Dio, 58, 22, 5.

${ }^{48}$ Suet., Tib., 53, 5 : proque tali clementia interponi decretum passus est, quo sibi gratiae agerentur et Capitolino Ioui donum ex auro sacraretur; Tac., Ann., 6, 25, 3: Eodem die defunctam quo biennio ante Seianus poenas luisset, memoriaeque id prodendum addidit Caesar. [...] Actae ob id grates, decretumque ut quintum decimum kalendas Nouembres, utriusque necis die, per omnes annos donum Ioui sacraretur.

${ }^{49}$ Suet., Tib., 53, 5 : quod non laqueo strangulatam in Gemonias abiecerit; Tac., Ann., 6, 25, 3: iactauitque quod non laqueo strangulata neque in Gemonias proiecta foret.

${ }^{50}$ J.-M. David, « Du Comitium à la roche Tarpéienne. Sur certains rituels d'exécution capitale sous la République, les règnes d'Auguste et de Tibère ", dans $D u$ châtiment dans la cité. Supplices corporels et peine de mort dans le monde antique. Table ronde organisée par l'EFR et avec le concours du CNRS (Rome, 9-11 novembre 1982), Rome, 1984, p. 131-176. Sur la privation de sépulture: F. Hinard, "La male mort: exécutions et statut du corps au moment de la première proscription », ibid., p. 295-311. 
mémoire ne pouvait donc pas être honorée. Tibère laissa mourir Drusus et Néron, et décida qu'il fallait disperser leurs restes ${ }^{51}$. Cette décision empêchait leurs funérailles puisque seul un corps entier ou reconstitué pouvait prétendre à un funus. Le Sénat avait donc la possibilité de décider de l'abolitio memoriae pour les membres de la domus Augusta. Ce pouvoir ne fut pas utilisé à la mort de Tibère. Les patres décidèrent qu'il pouvait bénéficier d'un funus publicum $^{52}$, mais ils refusèrent de lui accorder la consecratio, ainsi que les honneurs décernés au divin Auguste ${ }^{53}$, et la validité de son testament ${ }^{54}$, ce que ne fit que partiellement Caligula ${ }^{55}$. Cependant, il semblait encore difficile de condamner la mémoire d'un empereur. Il fallut le règne tyrannique de Caligula pour que la procédure législative d'abolitio memoriae apparaisse dans nos sources. Caligula fut le premier princeps victime d'un assassinat ${ }^{56}$. Les sénateurs ne se réunirent qu'une fois cette nouvelle connue et confirmée. Ils décidèrent de se rassembler au Capitole ${ }^{57}$. Ils refusaient de siéger dans une curie qui glorifiait la dynastie julio-claudienne. Pour la première fois, depuis le règne d'Auguste, le Sénat se réunit sans qu'aucun princeps ne soit désigné. Les sénateurs, sous la direction de Valerius Asiaticus ${ }^{58}$, votèrent un senatus consultum afin d'abolir les actes du princeps et de détruire les monuments qu'il avait fait construire ${ }^{59}$. Sa parenté immédiate aussi subit la damnatio memoriae, puisque sa fille et sa femme furent tuées ${ }^{60}$. Après son investiture, Claude refusa que l'on célèbre le jour de la mort de Caligula et ajouta à cette condamnation l'invalidation des acta de Caligula ${ }^{61}$. Celui-ci disparut de la liste des principes dans les serments et les prières officiels ${ }^{62}$. Bien que condamné à l'abolitio memoriae, le cadavre de Caligula fut enterré par son ami Agrippa, après n'avoir été brûlé qu'à demi,

\footnotetext{
${ }^{51}$ Suet., Tib., 54, 4 : Putant Neronem ad uoluntariam mortem coactum, cum ei carnifex quasi ex senatus auctoritate missus laqueos et uncos ostentaret, Druso autem adeo alimenta subducta, ut tomentum e culcita temptauerit mandere; amborum sic reliquias dispersas, ut uix quandoque colligi possent.

${ }^{52}$ Ios., A.J., 18, 236; Suet., Cal., 15, 1.

53 Dio, 59, 3, 7.

${ }^{54}$ Suet., Cal., 14, 1: Ingressoque urbem, statim consensu senatus et irrumpentis in curiam turbae, inrita uoluntate.

${ }^{55} \mathrm{Il}$ octroya les sommes dues aux soldats: Suet., Cal., 16, 8.

${ }^{56}$ Sur le récit de la mort de Caligula et le traitement réservé à sa mémoire, cf. J. Arce, Funus Imperatorum. Los funerales de los emperadores romanos, Madrid, 1988, p. 74.

${ }^{57}$ Suet., Cal., 60, 2 : ut consules primo non in curiam, quia Iulia uocabatur, sed in Capitolium conuocarent, quidam uero sententiae loco abolendam Caesarum memoriam ac diruenda templa censuerint; Claud., 10, 7.

${ }^{58}$ PIR, V, 25 ; RE, VII, A2, s.u. Valerius, col. 2342-2345, nº 106 (Weynand).

${ }^{59}$ Suet., Cal., 60, 2. Suétone amplifie les décisions des sénateurs puisqu'il indique que ces derniers voulurent effacer l'ensemble des temples et des actes de tous les principes. Dio, 60, 22, 3. Ce passage de Dion Cassius est à rapprocher d'un autre qui décrit de façon similaire la damnatio memoriae de Géta: Dio, 78, 12, 6.

${ }^{60}$ Sa fille, Milonia Iulia Drusilla: $P I R^{2}$, I 665 ; FOS, $n^{\circ}$ 438; sa femme, Caesonia: $P I R^{2}$, M 590, FOS, n 550. Cf. Suet., Cal., 59, 4: Perit una et uxor Caesonia gladio a centurione confossa et filia parieti inlisa; Ios., A.J., 19, 190; Dio, 59, 29, 7 ; Aur.Vic., 3, 16; Oro., 7, 6, 3.

${ }^{61}$ Suet., Claud., 11, 8: Gai quoque etsi acta omnia rescidit, diem tamen necis, quamuis exordium principatus sui, uetuit inter festos referri.

${ }^{62}$ Cette décision fut prise par un vote du Sénat: Dio, 60, 4, 6.
} 
hors du pomerium sur l'Esquilin, dans les horti Lamiani ${ }^{63}$. Il ne reçut les derniers honneurs qu'au retour d'exil de ses sœurs ${ }^{64}$. Suétone, dans ce passage, utilise le terme de cadauer pour décrire le corps de Caligula. Comme l'a bien démontré A. Allara ${ }^{65}$, ce terme est utilisé par les auteurs antiques pour décrire un cadavre qui ne peut recevoir de funérailles puisqu'il a subi des outrages. Le fait que les restes du princeps soient ensevelis hors du mausolée d'Auguste ${ }^{66}$ confirme que Caligula subit une condamnation tout comme les Julies.

Le deuxième princeps à avoir éventuellement subi une condamnation de mémoire est Néron ${ }^{67}$. À partir du moment où Galba accepta de rejoindre la révolte de Vindex ${ }^{68}$ et où la plèbe se mit à critiquer de plus en plus ouvertement Néron, le Sénat déclara celui-ci hostis publicus ${ }^{69}$, ce qui le condamnait au supplice de la fourche ${ }^{70}$. Lors de la même séance Galba fut désigné princeps. Cette décision fut prise par les sénateurs et acceptée par les prétoriens $^{71}$. Ces derniers refusèrent leur protection à Néron ${ }^{72}$ qui se retrouva seul, entouré de quelques affranchis et d'un eunuque qui l'aida à se donner la mort dans les faubourgs de Rome ${ }^{73}$. Le cadavre de Néron n'ayant subi

${ }^{63}$ Horti Lamiani: LTUR, III, Rome, 1996, p. 61-64 (M. Cima di Puolo); C. Häuber, Horti Romani. Die Horti Maecenatis und die Horti Lamiani auf dem Esquilin. Geschichte, Topographie, Statuenfunde, Francfort, 1991.

${ }^{64}$ Suet., Cal., 59, 2: cadauer eius clam in hortos Lamianos asportatum et tumultuario rogo semiambustum leui caespite obrutum est, postea per sorores ab exilio reuersas erutum et crematum sepultumque.

${ }^{65}$ A. Allara, "Corpus et cadauer. La gestion d'un nouveau corps ", dans F. Hinard dir., La mort au quotidien dans le monde romain. Actes du colloque organisé par l'université de Paris IV (ParisSorbonne, 7-9 octobre 1993), Paris, 1995, p. 69-79.

${ }^{66}$ Mausoleum Augusti: LTUR, III, p. 234-239 (H. von Hesberg et M. Maciocca).

${ }^{67} \mathrm{~J}$. Arce, Funus Imperatorum, cit. supra, p. 75-76.Voir notamment le débat sur le transfert ultérieur des cendres de Néron dans le mausolée d'Auguste. Sur le refus de considérer le sort réservé à Néron comme une abolitio memoriae, cf. E. Champlin, Nero, Cambridge, 2003. Toutefois, la déclaration d'hostis publicus associée à l'investiture de Galba le jour même de la décision sénatoriale nous autorise à intégrer Néron dans le corpus des empereurs qui ont subi une atteinte dans le traitement de leur mémoire.

${ }^{68} \mathrm{H}$. Mattingly, "The events of the last months of Nero, from the revolt of Vindex to the accession of Galba ", NC, 13, 1953, p. 3; M. Raoss, "La rivolta di Vindice ed il successo di Galba », Epigrafica, 20, 1958, p. 46-120; P.A. Brunt, "The revolt ofVindex and the Fall of Nero ", Latomus, 18, 1959, p. 531-559; H. Grassel, Untersuchungen zum Vierkaiserjahr 68/69 n. Chr. Ein Beitrag zur Ideologie und sozialstruktur des frühen Prinzipats, Vienne, 1973; K. Wellesley, The Long Year A.D. 69, Londres, 1975 ; R. J. A. Talbert, "Some causes of disorder in A.D. 68-69 », AJAH, 2, 1977, p. 69-85.

${ }^{69}$ Suet., Ner., 49, 2 : codicillos praeripuit legitque se hostem a senatu iudicatum et quaeri, ut puniatur more maiorum; Dio, 43, 27, 2b; Eutr., 7, 15, 1.

${ }^{70}$ La condamnation pour les déserteurs: Liu., Per., 55, 2 ; Suet., Ner., 41, 2 ; Epit., 5, 7 ; Eutr., 7, 15, 1; Isid., Orig., 5, 27, 34 .

${ }^{71}$ Dio, 43, 27, 2b ; 3; Ios., B.J., 4, 493; Aur.Vic., 5, 16; Epit., 5, 7 ; Eutr., 7, 15, 1.

${ }^{72}$ Tac., Hist., 1, 5, 1: Miles urbanus longo Caesarum sacramento imbutus et ad destituendum Neronem arte magis et impulsu quam suo ingenio traductus.

73 Suet., Ner., 48, 1: offerente Phaonte liberto suburbanum suum inter Salariam et Nomentanam uiam circa quartum miliarium, ut erat nudo pede atque tunicatus, paenulam obsoleti coloris superinduit adopertoque capite et ante faciem optento sudario equum inscendit, quattuor solis comitantibus, inter quos et Sporus erat ; 49, 2 ; 5 ; Dio, 43, 27, 2 ; 29, 3 ; Ios., B.J., 4, 493 ; Aur.Vic., 5, 16 ; Epit., 5, 7 ; Eutr., 
aucune mutilation ${ }^{74}$, il put recevoir un funus. Son corps fut brûlé après qu'un des affranchis de Galba en eut donné l'autorisation ${ }^{75}$. Son funus privé, luxueux, fut organisé par ses nourrices Eglogé et Alexandria ainsi que par sa concubine Actè. Ses cendres furent ensevelies dans le mausolée des Domitii ${ }^{76}$. Son tombeau fut à l'image de ses funérailles, grandiose et luxueux ${ }^{77}$. Tout comme Caligula, les cendres de Néron ne purent être ensevelies dans le mausolée d'Auguste. Le jour de sa déchéance fut aussi le premier jour du règne de Galba. L'investiture d'un nouveau princeps impliquait la condamnation de son prédécesseur, s'il n'était pas mort naturellement.

Les sources ne nous fournissent que peu d'indications sur les sanctions prises à l'encontre de Galba ${ }^{78}$. Cependant, en analysant les descriptions de son funus, nous pouvons considérer que, dans un premier temps, il subit une damnatio memoriae. En effet, son corps fut outragé. Il fut décapité, l'un de ses assassins lui trancha la tête afin de l'apporter à Othon ${ }^{79}$. Finalement, elle fut donnée aux esclaves de Patrobius, une ancienne victime de Galba. Ses derniers lui firent subir de nombreux outrages ${ }^{80}$. Cependant, Galba put, avec l'autorisation d'Othon, recevoir des funérailles qui furent organisées de nuit par Argius, son affranchi ${ }^{81}$. Son corps put recevoir les derniers honneurs car il était complet ${ }^{82}$. Il fut enterré dans ses anciens jardins ${ }^{83}$. Il ne reçut pas les honneurs d'un funus

7, 15, 1; Oro., 7, 7, 13. Cf. J. Scheid, « La mort du tyran. Chronique de quelques morts programmées ", dans Du châtiment dans la cité, cit. supra, p. 177-193; B. R. Reece, "The date of Nero's death ", AJPh, 91, 1969, p. 72-74; nia Salaria: LTUR, V, Rome, 1999, p. 144-145 (J. R. Patterson); uia Nomentana: LTUR,V, p. 142 (J. R. Patterson).

${ }^{74}$ Suet., Ner., 49, 8; Dio, 63, 27, 3.

75 Suet., Ner., 40, 9: Permisit hoc Icelus, Galbae libertus.

${ }^{76}$ Suet., Ner., 50, 1-2: Funeratus est impensa ducentorum milium, stragulis albis auro intextis, quibus usus Kal. Ian. fuerat. Reliquias Egloge et Alexandria nutrices cum Acte concubina gentili Domitiorum monumento condiderunt, quod prospicitur e campo Martio impositum colli Hortulorum. Sur le sepulchrum Domitii: LTUR, IV, Rome, 1999, p. 286-288; A. M. Colini, « La tomba di Nerone », CollSod, 5, 1975-1976, p. 35-40.

77 Suet., Ner., 50, 3: In eo monumento solium porphyretici marmoris, superstante Lunensi ara, circumsaeptum est lapide Thasio.

78 J. Arce, Funus Imperatorum, cit. supra, p. 77.

${ }^{79}$ Suet., Galb., 20, 5 : Ingulatus est ad lacum Curti ac relictus ita uti erat, donec gregarius miles a frumentione rediens abiecto onere caput, ei amputauit; et quoniam capillo arripere non poterat ad Othonem detulit. Ille lixis calonibusque donanit, qui hasta suffixum non sine ludibrio circum castra.

${ }^{80} P^{2}$, P 161 ; RE, XVIII, 4, 1949, s.u. Patrobius, col. 2253 (A. Stein); Suet., Galb., 20, $7: A b$ is Patrobii Neroniani libertus centum aureis redemptum eo loco, ubi iussu Galbae animaduersum in patronum suum fuerat, abiecit; Tac., Hist., 1, 49, 1: Caput per lixas calonesque suffixum laceratumque Patrobii tumulum - libertus is Neronis punitus a Galba fuerat; Plut., Galb., 17, 2-3. Y. Rivière, Le cachot et les fers : détention et coercition à Rome, Paris, 2004, p. 82-83, démontre que les cadavres des principes sont généralement outragés sur les lieux de leurs excès.

${ }^{81}$ Suet., Galb., 20, 8: Sero tandem dispensator Argiuus et hoc et ceterum truncum in priuatis eius hortis Aurelia nia sepultura dedit; Tac., Hist., 1, 48, 2; 49, 1 : Galbae corpus diu neglectum et licentia tenebrarum plurimis ludibriis nexatum dispensator Argius e prioribus seruis humili sepultura in priuatis eius hortis contexit; Plut., Galb., 28, 4.

82 Tac., Hist., 1, 49, 1 : postera demum die repertum et cremato iam corpori admixtum est.

${ }^{83}$ Horti, Galba: LTUR, III, p. 60 (E. Papi); P. Grimal, Les jardins romains à la fin de la République et aux premiers siècles de l'Empire. Essai sur le naturalisme romain, Rome, 1984, p. 159-161. 
publicum et fut enterré dans l'une de ses demeures afin qu'aucun culte public ne puisse lui être rendu.

Domitien fut assassiné dans sa chambre, en septembre 96, par ses proches aidés par l'intendant Stephanus, le corniculaire Clodianus, Maximus, un affranchi, et des gladiateurs ${ }^{84}$. Il combattit ses adversaires comme un gladiateur dans l'arène ${ }^{85}$. D'ailleurs, les sources tardives évoquent pour cet empereur un funus more gladiatorio ${ }^{86}$. Cette mort est indigne d'un bon citoyen puisqu'il s'agit de la même mort que pour un parricide ${ }^{87}$. Les sénateurs se réunirent dans la curie, à l'annonce de son décès, afin de voter la damnatio memoriae qui consistait à retirer ses clipei, ses portraits ainsi qu'à effacer son nom des inscriptions ${ }^{88}$. Domitien est le premier princeps dont les sources littéraires affirment qu'il subit une abolitio memoriae ${ }^{89}$. Cette condamnation est confirmée par les nombreuses érasures de sa titulature que nous connaissons ${ }^{90}$. Malgré tout, il bénéficia de funérailles organisées par sa nourrice, hors du pomerium ${ }^{91}$. À la différence des autres empereurs condamnés, Domitien put être enterré auprès de ses ascendants. Après la crémation, ses cendres furent transportées au templum gentis Flauiae. Ce dernier avait été construit par lui-même afin que la dynastie flavienne pût aussi avoir un mausolée. Une fois le temple terminé, il avait fait transférer les cendres de Vespasien du mausolée d'Auguste au templum gentis Flaniae ${ }^{92}$. Les sénateurs ayant aboli les acta de Domitien, on peut donc se

${ }^{84}$ Suet., Dom., 16, 7 : Itaque summotis omnibus in cubiculum se recepit atque ibi occisus; 17, 1-4. Stephanus: PIR 2 , S 899; RE, III, A, 2, 1929, s.u. Stephanos, col. 2363-2364, n. 7 (A. Stein); Clodianus: PIR 2 C, 1151 ; RE, IV, 1, 1900, s.u. Clodianus, col. 63, n. 2 (E. Groag).

${ }^{85}$ Suet., Dom., 17, 5 ; Dio, 67, 17. Sur la comparaison entre Domitien et un gladiateur: Plin., Pan., 33, 3-4; J. Arce, Funus Imperatorum, cit. supra, p. 82.

${ }^{86}$ Aur.Vic., 11, 8; Epit., 11, 13; Eutr., 7, 23, 6. La mort du gladiateur résulte d'un égorgement: G.Ville, La gladiature à Rome d'Auguste à Domitien, Rome, 1981, p. 425-426.

${ }^{87}$ Cic., Cat., 1, 17; Y.Thomas, "Parricidium I. Le père, la famille et la cité (la lex Pompeia et le système des poursuites politiques)", MEFRA, 93, 1981, p. 643-715.

${ }^{88}$ Suet., Dom., 23, 2: ut repleta certatim curia non temperaret, quin mortuum contumeliosissimo atque acerbissimo adclamationum genere laceraret, scalas etiam inferri clipeosque et imagines eius coram detrahi et ibidem solo affligi iuberet, nouissime eradendos ubique titulos. La destruction des statues fut spontanée à l'annonce de la mort de Domitien: Plin., Pan., 52, 4.

${ }^{89}$ Suet., Dom., 23, 2 : abolendamque omnem memoriam decerneret; Lact., Mort., 3, 2-4.

${ }^{90}$ A. Martin, La titulature épigraphique de Domitien, Francfort, 1987; H. I. Flower, "A tale of two monuments: Domitian, Trajan, and some Praetorian at Puteoli $(A E, 1973,137)$ ", AJA, 105, 2001, 1, p. 625-648; J.-M. Pailler, "Damnatio memoriae: une véritable perpétuité ", Pallas, 40, 1994, p. 11-55 ; A. Martin, «La condamnation de la mémoire de Domitien, état de la question », dans S. Benoist éd., Mémoire et histoire. Les procédures de condamnation dans l'Antiquité romaine, Metz, 2007, p. 59-72.

${ }^{91}$ Suet., Dom., 17, 7 : cadauer eius populari sandapilla per uispillones exportatum Phyllis nutrix in suburbano suo Latina uia funerauit, sed reliquias templo Flauiae gentis clam intulit cineribusque Iuliae Titi filiae, quam et ipsam educarat, commiscuit.

${ }_{92}$ Gens Flauia, templum: LTUR, II, Rome, 1995, p. 368-369 (F. Coarelli); E. La Rocca, «Il templum gentis Flaviae", dans F. Coarelli éd., Divus Vespasianus, Milan, 2009, p. 224-233; K. Scott, The Imperial Cult under the Flavians, Stuttgart, 1936, p. 64-65; M. Torelli, "Culto imperiale e spazi urbani in età flavia, dai rilievi Hartwig all'arco di Tito ", dans L'Vrbs: espace urbain et histoire (Ir siècle avant J.-C.-III siècle après J.-C.), Rome, 1987, p. 563-582. 
demander si ce transfert de cendres était reconnu par eux. Ainsi, les cendres de Domitien ne reposeraient qu'avec celles de sa nièce Julie ${ }^{93}$.

Les femmes les plus proches de l'empereur pouvaient, elles aussi, faire l'objet d'une condamnation de mémoire. Ce fut d'abord le cas de Messaline en 38 apr. J.-C., puis celui d'Agrippine, sous le règne de Néron, en 59 apr. J.-C. ${ }^{94}$ Dans le cas de ces deux femmes, le Sénat intervint, comme l'atteste le vocabulaire utilisé par Tacite (iunitque oblinionem eius senatus; decernentur... statuarentur). Il prit les décisions suivantes: dans le cas de Messaline, son nom et ses imagines furent enlevés de tous les lieux publics et privés, dans le cas d'Agrippine, en plus d'obsèques misérables, son anniversaire devint un jour néfaste.

\section{Les particuliers condamnés de mémoire}

Le fait que les empereurs aient pu faire l'objet d'atteintes à la mémoire provoqua deux changements importants: l'investissement du Sénat dans la prise de décision et l'inscription de ces mesures dans la sphère publique. Ces deux éléments traduisent donc ce que devient, sur le plan juridique, l'abolitio memoriae au I ${ }^{\text {er }}$ siècle apr. J.-C. L'instauration de cette procédure, à travers les figures impériales, va avoir comme principale conséquence de permettre son extension à des personnes extérieures à l'empereur et sa famille. Par la généralisation de cette procédure, des particuliers vont pouvoir, après le règne de Tibère, être frappés de condamnation de mémoire d'une manière très différente de l'usage républicain.

Ainsi, plusieurs atteintes furent décidées contre les écrivains sous les règnes de Tibère et de Néron ${ }^{95}$. Il s'agissait de détruire leurs œuvres par le feu. Caligula envisagea même la destruction des œuvres d'Homère et de Virgile. Dans le cadre de mesures répressives d'ordre politique, les empereurs décidèrent de faire voter à de multiples reprises des destructions de statues de personnages célèbres. Ce fut le cas sous Tibère en 24 , avec la destruction de la statue de Silius le père, rappelée par Tacite dans son récit de la condamnation de Messaline et de Silius le fils ${ }^{96}$. Quant à Caligula, il décida de porter atteinte aux illustres personnages honorés par Auguste sur son forum ${ }^{97}$. Sous Néron, il fut interdit d'honorer l'imago du républicain C. Cassius ${ }^{98}$. Le Sénat intervint pour interdire la célébration des imagines de Livia Drusilla, condamnation qui, cette fois, ne concerna que la sphère privée ${ }^{99}$. Les atteintes à la mémoire pouvaient aussi concerner les noms de personnes, comme ce fut le cas dans la gens des Drusus où le praenomen Lucius ne put être porté en raison de la condam-

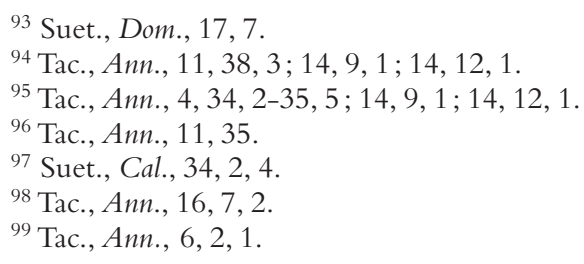


nation pour brigandage d'un Lucius Drusus ${ }^{100}$. Sous Néron, il fut encore décidé de changer le nom du mois de juin en raison de la condamnation de deux Iunii Torquati ${ }^{101}$.

\section{LES RÉACTIONS POPULAIRES}

Lors des différentes condamnations évoquées, la plèbe et les corps armés peuvent avoir des attitudes violentes qui ne correspondent pas toujours aux décisions prises par le Sénat. Dans les sources, nous observons deux types de réactions: les réactions de la foule et des armées.

\section{Les condamnations réclamées par le peuple}

Lors du procès contre $\mathrm{Cn}$. Pison, la plèbe menaça les sénateurs afin qu'ils ne soient pas trop cléments envers l'accusé ${ }^{102}$. Elle avait jeté ses statues aux Gémonies anticipant sa future condamnation ${ }^{103}$. Tibère refusa cet excès de violence et ordonna de replacer les statues et de protéger Cn. Pison durant son procès $^{104}$.

Tibère mourut à Misène le 16 mars $37^{105}$. Lors de la translatio cadaueris, les réactions des Italiens furent inverses de celles observées lors de retour du corps d'Auguste. La dépouille de Tibère ne fut pas acclamée, les habitants n'exprimèrent pas leur tristesse mais leur joie de voir le jeune Caligula mettre fin à un long règne de tyrannie. À Rome, la plèbe souhaita que Tibère soit jeté au Tibre et son corps exposé aux Gémonies, comme celui de nombreux citoyens au cours de son règne ${ }^{106}$. Cependant, Suétone indique que face à la violence spontanée de la foule ${ }^{107}$, ce furent les soldats qui portèrent et défendirent le corps à Rome, afin que Tibère pût bénéficier d'un funus publicum.

\footnotetext{
100 Suet., Tib., $1,4$.

101 Tac., Ann., 16, 12, 2.

102 Tac., Ann., 3, 14, 4: Simul populi ante curiam uoces audiebantur: non temperaturos manibus si patrum sententias euasisset. Cf. W. D. Lebek, "Roms Ritter und Roms Plebs in den Senatsbeschlüssen für Germanicus Caesar und Drusus Caesar », ZPE, 95, 1993, p. 81-120.

103 Tac., Ann., 3, 14, 4: Effigiesque Pisonis traxerant in Gemonias ac diuellebant.

${ }^{104}$ Tac., Ann., 3, 14, 5 : Ni iussu principis protectae repositaeque forent. Igitur inditus lecticae et a tribuno praetoriae cohortis deductus est, uario rumore custos saluti an mortis exactor sequeretur.

105 Suet., Tib., 73, 2; Dio, 58, 28, 1.

106 Ios., A.J., 18, 225; Suet., Tib., 75, 1 : Morte eius ita laetatus est populus, ut ad primum nuntium discurrentes pars "Tiberium in Tiberim! " clamitarent, pars Terram matrem deosque Manes orarent ne mortuo sedem ullam nisi inter impios darent, alii uncum et Gemonias cadaueri minarentur, exacerbati super memoriam pristinae crudelitatis etiam recenti atrocitate; 75, 4: creuit igitur, quasi etiam post mortem tyranni saeuitia permanente; Cal., 13, 2; Eutr., 7, 11, 3. Cf.Y. Rivière, Le cachot et les fers, cit. supra,

${ }^{107}$ L'auteur fait une différence entre la joie du populus et la violence de la foule dont nous ne pouvons connaitre la teneur.
} p. $82-83$. 


\section{Les oppositions du peuple aux condamnations}

Malgré l'état fragmentaire du livre V des Annales de Tacite, ce dernier fournit des indications sur le déroulement de la condamnation de Drusus et de Néron. Tibère demanda au Sénat de les déclarer tous deux hostes publici. À la suite de la lecture de la lettre de Tibère, le consulaire M. Aurelius Cotta Messalinus demanda à débattre de la question ${ }^{108}$. Sous la pression de la plèbe, qui portait les portraits d'Agrippine et de Néron, la question fut reportée $\mathrm{e}^{109}$. Cependant, cette décision ne calma pas la plèbe, qui décida de s'armer afin de défendre la famille de celui qui avait été co-régent ${ }^{110}$. Le princeps dut renouveler sa missive et condamner la plèbe dans un édit ${ }^{111}$.

Une des grandes pages tragiques de Tacite est consacrée à l'opposition du peuple au traitement infâmant réservé à la première épouse de Néron, Octavie $^{112}$. En réalité, Tacite a évoqué les sentiments de sympathie de la foule vis-à-vis d'Octavie et d'hostilité à Poppée avant la mise à mort épouvantable de celle qui est sacrifiée ${ }^{113}$. Mais on peut faire le parallèle entre les deux récits tant il y a une disproportion entre la célébration d'Octavie par le peuple et le caractère infâmant de la mort qui lui est imposée.

À la mort de Domitien, les sénateurs manifestèrent leur allégresse alors que les soldats souhaitaient que ses meurtriers soient châtiés et que les honneurs divins lui soient votés; quant à la plèbe, elle resta indifférente ${ }^{114}$. Les troubles de l'ordre public purent être évités par l'investiture rapide de Nerva ${ }^{115}$.

${ }^{108}$ Tac., Ann., 5, 3, 2 : in nurum ne id quidem confingere ausus, adrogantiam oris et contumacem animum incusauit, magno senatus pauore ac silentio, donec pauci, quis nulla ex honesto spes - et publica in occasionem gratiae trahuntur - ut referrretur postulauere, promptissimo Cotta Messalino cum atroci sententia. Sur Aurelius Cotta Messalinus: $P_{R^{2}}$, A 1488; RE, II, 2, 1896, s.u. Aurelius, col. 24892491, n. 111 (P. von Rohden), celui-là même qui prononça la sentence contre Libo Drusus; S. H. Rutledge, Imperial Inquisitions Prosecutors and Informants from Tiberius, Londres, 2001; Y. Rivière, Le cachot et les fers, cit. supra, n. 254.

109 Tac., Ann., 5, 4, 2: Simul populus, effigies Agrippinae ac Neronis gerens, circumsistit curiam faustisque in Caesarem ominibus falsas litteras et principe inuito exitium domui eius intendi clamitat. Ita nihil triste illo die patratum.

110 Tac., Ann., 5, 4, 4: Vnde illa ira uiolentior et materies criminandi: spretum dolorem principis ab senatu, desciuisse populum; audiri iam et legi nouas contiones, noua patrum consulta; quid reliquum nisi ut caperent ferrum et, quorum imagines pro uexillis secuti forent, duces imperatoresque deligerent?

111 Tac., Ann., 5, 5, 1: Igitur Caesar, repertitis aduersum nepotem et nurum probris increpitaque per edictum plebe, questus apud patres quod fraude unius senatoris imperatoria maiestas elusa publice foret, integra tamen sibi cuncta postulauit.

${ }^{112}$ Tac., Ann., 14, 64, 2; PIR ${ }^{2}$, C 1110 ; RE, III 2, 1899, col. 2893 et suiv., n 428 (S. Brasloff); Ps. Sen., Octavie, v. 792 et suiv.

113 Tac., Ann., 14, 60, 5-61, 1.

114 Suet., Dom., 23, 1-2: Occisum eum populus indifferenter, miles grauissime tulit statimque Diuum appellare conatus est, paratus et ulcisci, nisi duces defuissent; quod quidem paulo post fecit expostulatis ad poenam pertinacissime caedis auctoribus. Contra senatus adeo laetatus est. Cf. Z. Yavetz, "The urban Plebs in the days of the Flavians, Nerva and Trajan ", dans Oppositions et résistances à l'Empire d'Auguste à Trajan, Genève, 1987, p. 131-187.

115 D. Kienast, Römische Kaisertabelle. Grundzüge einer römischen Kaiserchronologie, $2^{\mathrm{e}}$ éd., Darmstadt, 1996, p. 120-121; PIR², C 1227 ; RE, IV, 1, 1900, s.u. Cocceius, col. 133-154, n. 16 


\section{Les réactions militaires}

L'armée est l'autre cadre, à côté de la foule présente dans la cité, au sein duquel une expression populaire peut se faire entendre à propos du traitement imposé à la mémoire d'un personnage public. C'est par leurs enseignes que les soldats honorent ou détruisent l'imago d'un empereur. Durant les événements de l'année 68-69 apr. J.-C., deux empereurs virent leurs imagines détruites sur les enseignes militaires. Ce fut d'abord le cas de Galba, puis celui de Vitellius ${ }^{116}$. Sous Tibère déjà, les légions de Syrie avaient été louées et avaient reçu des présents pour n'avoir pas honoré, sur leurs enseignes, la figure de Séjan ${ }^{117}$.

\section{RÉHABILITER LA MÉMOIRE ET ANTICIPER UNE CONDAMNATION}

\section{Une réhabilitation possible}

Quelques principes décidèrent de rétablir la mémoire de certains condamnés. Caligula, comme premier acte de son principat, rendit les derniers hommages à sa mère et à ses frères. Il organisa même une translatio cinerum avant de déposer leurs cendres dans le mausolée d'Auguste ${ }^{118}$. Le princeps décida d'annuler certaines initiatives hostiles prises par Tibère en instituant les célébrations des anniversaires des membres défunts de sa famille ${ }^{119}$. Le fait de déposer les cendres de sa mère et de ses deux frères dans le mausolée dynastique permettait à Caligula de mettre un terme à leur damnatio memoriae. Cette réhabilitation fut confirmée par l'érection de nouvelles statues à leur effigie lors du consulat de Claude ${ }^{120}$.

(A. Stein). Nerva obtint l'ensemble de ses pouvoirs le jour de la mort de Domitien: P. Kneissl, Die Siegestitulatur der römischen Kaiser, Göttingen, 1969, p. 58-66; A. Chastagnol, «Un chapitre négligé de l'épigraphie latine: la titulature des empereurs morts ", REL, 62, 1984, p. 275-287 $(=\mathrm{S}$. Benoist et S. Demougin éd., Le pouvoir impérial à Rome: figures et commémorations. Scripta varia $I V$, Genève, 2008, p. 119-131).

${ }^{116}$ Galba:Tac., Hist., 1, 41, 1; 55, 3; 36, 1; 56, 1; PIR, S 723; RE, IV, A1, 1931, col. 772 et suiv., $\mathrm{n}^{\circ} 63$ (M. Fluss).Vitellius: Tac., Hist., 3, 13, 1; 2, 85, 1; 3, 31, 2; 3, 85; PIR, V 499; RE, Suppl. IX, 1962, col. 1706 et suiv., $n^{\circ} 7 b$ (G. Winkler).

117 Suet., Tib., 48, 4.

118 Suet., Cal., 15, 1-2: Incendebat et ipse studia hominum omni genere popularitatis. Tiberio cum plurimis lacrimis pro contione laudato funeratoque amplissime, confestim Pandateriam et Pontias ad transferendos matris fratrisque cineres festinauit, tempestate turbida, qui magis pietas emineret, additque uenerabundus ac per semet in urnas condidit; nec minore scaena Ostiam praefixo in biremis puppe uexillo et inde Romam Tiberi subuectos per splendidissimum quemque equestris ordinis medio ac frequenti die duobus ferculis Mausoleo intulit inferiasque is annua religione publice instituit, et eo amplius matri circenses carpentumque quo in pompa traduceretur.

${ }^{119}$ Depuis 33, la date de la mort d'Agrippine était commémorée par un sacrifice à Jupiter Capitolin. CFA, n. 13 f, 1. 10-16.

${ }^{120}$ Suet., Claud., 9, 1 : sed ne discrimibus quidem caruit. Primum in ipso consulatu, quod Neronis et Drusi fratrum Caesaris statuas segnius locandas ponendasque curasset, paene honore summotus est. 
Othon puis Vitellius voulurent rétablir la mémoire de Néron sans obtenir l'accord du Sénat ${ }^{121}$. Les couches inférieures de la plèbe refusèrent de reconnaître le statut de damnatus de Néron. Elles qualifièrent Othon de Néron ${ }^{122}$. Othon accepta les honneurs qu'une partie de la plèbe lui rendit afin d'éviter une nouvelle guerre civile à Rome entre les partisans de Néron et ceux de l'aristocratie sénatoriale. Cette attitude apparaît ambiguë dans les sources ${ }^{123}$. En effet, Othon accepta que des statues de Néron soient relevées et continua la construction de la domus Aurea, alors que ce lieu était le symbole de l'arbitraire du pouvoir néronien ${ }^{124}$. De plus, il signa certains de ses édits du nom de Néron. Cependant, face au mécontentement d'une partie des magistrats, il mit fin à cette pratique ${ }^{125}$.

Vitellius voulut rendre un culte à Néron, bien que le Sénat n'eût pas voté la consecratio de ce dernier ${ }^{126}$. Il ne faisait que répondre à l'attente d'une partie de la plèbe qui venait régulièrement fleurir la tombe de Néron ${ }^{127}$.

${ }^{121}$ Tacite précise qu'Othon obtint par le vote d'un sénatus-consulte le rétablissement de la mémoire de Poppée, alors que le rétablissement de la mémoire de Néron semble dû aux pressions de la plèbe et des soldats: Tac., Hist., 1, 78, 2: ne tum quidem immemor amorum statuas Poppaeae per senatus consultum reposuit; creditus est etiam celebranda Neronis memoria agitauisse spe nolgum adliciendi.

${ }^{122}$ Suet., Oth., 7, 2: Ac super ceteras gratulantium adulantiumque blanditias ab infima plebe appellatus Nero nullum indicium recusantis dedit; Tac., Hist., 1, 78, 2 : atque etiam Othoni quibusdam diebus populus et miles, tamquam nobilitatem ac decus adstruerent, Neroni Othoni acclamanit; Plut., Oth., 3, 1. Cf. L. Gavazzi, "Alcuni aspetti della popularitas di Nerone ", AIV, 134, 1975-1976, p. 421437 ; R. Carré, "L'utilisation du nom de Néron dans les Histoires de Tacite ", ALMArv, 15, 1988, p. 15-22; Id., "Othon et Vitellius, deux nouveaux Nérons? ", dans J.-M. Croisille, R. Martin, Y. Perrin éd., Neronia V. Néron: histoire et légende. Actes du $V^{e}$ Colloque international de la SIEN (Clermont-Ferrand et Saint-Étienne, 2-6 novembre 1994), Bruxelles, 1999, p. 152-181; E. Flaig, "Wie kaiser Nero die Akzeptanz bei der Plebs urbana verlor. Eine Fallstudie zum politischen Gericht im Prinzipat », Historia, 52, 2003, p. 351-372.

123 Tac., Hist., 1, 78, 2: Ipse in suspenso tenuit, uetandi metu uel adgnoscendi pudore. Cf. B. H. Stolte, "Tacitus on Nero and Otho ", AncSoc, 4, 1973, p. 177-190; M. Labate, "Le ambiguità di Otone ", Maia, 29-30, 1977-1978, p. 27-60; Y. Shochat, "Tacitus' attitude to Otho ", Latomus, 40, 1981, p. 365-377.

${ }^{124}$ Domus Aurea: LTUR, II, p. 48-64 (A. Cassatella). Suet., Oth., 7, 3: nec quicquam prius pro potestate subscripsit quam quingenties sestertium ad peragendam Auream domum; Plut., Oth., 3, 1. Cette construction sera remise en cause sous les Flaviens: J. Elsner, "Constructing Decadence: The Representation of Nero as Imperial Builder ", dans J. Elsner, J. Master éd., Reflections of Nero : Culture, History and Representation, Londres, 1994, p. 112-117; F. Ripoll, " Aspects et fonctions de Néron dans la propagande flavienne ", dans J.-M. Croisille, R. Martin, Y. Perrin éd., Neronia $V$, cit. supra, p. 137-151; A. Daguet-Gagey, «La damnatio memoriae dans l'espace urbain: les avatars de quelques monuments romains ", dans S. Benoist éd., Mémoire et histoire, cit. supra, p. 113129; E. Rosso, "Les destins multiples de la domus Aurea. L'exploitation de la condamnation de Néron dans l'idéologie flavienne ", dans S. Benoist, A. Daguet-Gagey éd., Un discours en images de la condamnation de mémoire, Metz, 2008, p. 43-79.

${ }^{125}$ Suet., Oth., 7, 2 ; Plut., Oth., 3, 2.

${ }^{126}$ Suet., Vit., 11, 3 : Et ne cui dubium foret, quod exemplae egendae rei publice eligeret, medio Martio campo adhibita publicorum sacerdotum frequentia inferias Neroni dedit; Dio, 64, 7, 3.

127 Suet., Ner., 57, 2: Et tamen non defuerunt qui per longum tempus uernis aestiuisque floribus tumulum eius ornarent; Tac., Hist., 2, 95, 1: Laetum foedissimo cuique, apud bonos invidiae fuit quod exstructis in Campo Martio aris inferias Neroni fecisset. Caesae publice uictimae cremataeque; facem Angustales subdidere, quod sacerdotium, ut Romulus Tatio regi, ita Caesar Tiberius Inliae genti sacranit. 
Toutefois, les membres de l'aristocratie n'acceptèrent pas de voir la mémoire de ce dernier rétablie sans vote d'un sénatus-consulte. La condamnation fut maintenue puisque les acta Neronis ne furent pas reconnus par les Flaviens, comme en témoigne la rédaction de la lex de imperio Vespasiani ${ }^{128}$. Vespasien comprit l'importance de ne pas réhabiliter Néron. Il fit détruire une grande partie des monuments construits par celui-ci et surtout, d'une manière systématique, il fit disparaitre les dédicaces faites par le dernier des JulioClaudiens ${ }^{129}$. La décision sénatoriale de condamner la mémoire de Néron fut difficilement applicable en raison de sa grande popularité auprès de la plèbe. Othon et Vitellius, ayant été des proches de Néron, durent donc trouver une attitude qui satisfit aussi bien l'aristocratie que la plèbe. En raison de sa victoire lors du bellum ciuile, Vespasien put se permettre d'appliquer la sentence sénatoriale.

Dès l'annonce du suicide d'Othon et de l'acclamation de Vitellius, le Populus Romanus organisa une cérémonie en l'honneur de Galba et le Sénat lui vota l'érection d'une statue sur le forum ${ }^{130}$. Vespasien condamna le meurtre de ce princeps et fit réinstaller ses imagines dans les municipes. Puis, Domitien proposa au Sénat de restaurer les honneurs de Galba ${ }^{131}$. Cette réhabilitation fut possible en raison de l'attitude noble de Galba lors de son assassinat. Les sources littéraires transmettent deux versions de sa mort. Dans l'une, son attitude fut suppliante, dans l'autre, son attitude fut digne d'un princeps: Galba offrit sa gorge en sacrifice à ses assaillants pour le bien du Populus Romanus et de la Res Publica, afin d'éviter un nouveau bellum cinile ${ }^{132}$. Il affronta la mort

${ }^{128}$ F. Hurlet, "La lex de Imperio Vespasiani et la légitimité augustéenne », Latomus, 52, 1993, p. 261-280.

${ }^{129}$ E. S. Ramage, «Denigration of a Predecessor under Claudius, Galba, Vespasien », Historia, 32, 1983, p. 200-214; Id., "Juvenal and the Establishment: Denigration of a Predecessor in the Satires ", ANRW, 33, Berlin-New York, 1989, p. 640-707; M. Torelli, "Culto imperiale e spazi urbani in età flavia ", cit. supra, p. 563-582; W. Eck, "Die Vernichtung der memoria Neros: Inschriften der neronischen Zeit aus Rom ", dans J.-M. Croisille,Y. Perrin éd., Neronia VI. Rome à l'époque néronienne: institutions et vie politique, économie et société, vie intellectuelle, artistique et spirituelle, Bruxelles, 2002, p. 285-295.

${ }^{130}$ Suet., Galb., 23, 1 : Senatus, ut primum licitum est, statuam ei decreuerat rostratae columnae superstantem in parte fori, qua trucidatus est; sed decretum Vespasianus aboleuit; Tac., Hist., 2, 55, 1-2.

${ }^{131}$ Tacite, dans sa description du meurtre de Galba, condamne cet acte sacrilège commis dans le pomerium au plus près des temples: Tac., Hist., 1, 40, 2: Igitur milites Romani, quasi Vologaesum aut Pacorum auito Arsacidarum solio depulsuri ac non imperatorem suum inermem et senem trucidare pergerent, disiecta plebe, proculcato senatu, truces armis, rapidi equis forum inrumpunt. Nec illos Capitolii adspectus et imminentium templorum religio et priores et futuri principes terruere quo minus facerent scelus, cuius ultor est quisquis successit. Cf. J. Gagé, "Vespasien et la mémoire de Galba », REA, 54, 1952, p. 290-315; M. Fuhrmann, «Das Vierkaiserjahr bei Tacitus. Über dem aufbau der Historien Buch I-III ", Philologus, 104, 1960, p. 250-278. Sur la réinstallation des imagines, Tac., Hist., 3, 7, 2 : Desiderata diu res interpretatione gloriaque in maius accipitur, postquam Galbae imagines discordia temporum subuersas in omnibus municipiis recoli iussit Antoninus, decorum pro causa ratus, si placere Galbae principatus et patres renirescere crederentur. Sur la restauration des honneurs par Domitien, Tac., Hist., 4, 4, 1: Referente Caesare de restituendis Galbae honoribus.

132 Attitude suppliante: Suet., Galb., 20, 1; Tac., Hist., 1, 49, 2; Dio, 64, 6, 4. Attitude digne d'un princeps: Suet., Galb., 20, 1: Plures autem prodiderunt optulisse ultro iugulum et "ut hoc agerent 
comme se devait de le faire un bon citoyen romain ${ }^{133}$. Cette attitude s'oppose à la cruauté et à l'acharnement bestial dont firent preuve ses assassins, selon Tacite et Suétone ${ }^{134}$. La réhabilitation de Galba est attestée par la présence de son nom dans la lex de imperio Vespasiani et sur la Tabula Banasitana ${ }^{135}$. L'utilisation par Tacite du terme de corpus pour décrire le cadavre de Galba est aussi une indication de cette réhabilitation.

\section{Anticiper la condamnation}

Othon se suicida sur le champ de bataille de Bédriac après la défaite de ses troupes ${ }^{136}$. Dans ses derniers moments, il se comporta comme un princeps avisé en faisant évacuer du camp les membres de l'aristocratie sénatoriale et équestre qui lui avaient apporté leur soutien. Il brûla aussi les lettres qui pouvaient mettre en danger certains de ses partisans ${ }^{137}$. Cette attitude honorable à l'approche de la mort permit à Othon de ne pas apparaitre comme un tyran dans les sources littéraires ${ }^{138}$. Il demanda à Messaline de protéger sa mémoire et sa dépouille ${ }^{139}$. Son attitude à ses derniers instants et sa demande de protection ne l'empêchèrent pas de subir une condamnation de mémoire. Il fut exclu de la liste des principes cités dans les textes épigraphiques, ce qui implique une condamnation de ses acta. Ses soldats décidèrent d'enterrer rapi-

ac ferirent, quando ita nideretur "; Tac., Hist., 1, 49, 2 : plures obtulisse ultro percussoribus ingulum : agerent ac ferirent, si ita $\left\langle_{e}\right\rangle$ re publica uideretur. Non interfuit occidentium quid diceret; Plut., Galb., 27, 1. Cf. B. Mouchova, "Suetonius und Tacitus über die Todesumstände Galbas », ZJKF, 7, 1966, p. 5-8; M. C. Mittelstadt, «Tacitus and Plutarch. Some interpretative methods », RSC, 15, 1967, p. 293-302 ; P.Venini, « SulleVite suetoniane di Galba, Otone eVitellio », RIL, 108, 1974, p. 9911004 ; L. Braun, "Galba und Otho bei Plutarch und Sueton ", Hermes, 120, 1992, p. 90-102.

133 J.-L.Voisin, "Le muet et le bavard ", dans F. Hinard dir., La mort, les morts et l'au-delà dans le monde romain, Caen, 1987, p. 247-255.

134 Tac., Hist., 41, 3; Suet., Galb., 20, 5-6.

135 Tab. Banasitana (IAM, II, 94), 1. 20; W. Seston, M. Euzennat, "Un dossier de la chancellerie romaine: la Tabula Banasitana. Étude de diplomatie ", CRAI, 1971, p. 468-490.

${ }^{136}$ Ios., B.J., 4, 548; Suet., Oth., 11, 3; Tac., Hist., 2, 49, 2-3; Plut., Oth., 17, 5; Dio, 63, 15 , $1^{2}$; Epit., 7, 2; Eutr., 17, 3; Oros., 7, 8, 6. Cf. R. Hanslik, "Die Auseinandersetzung zwischen Otho und Vitellius bis zur Schlacht von Bedriacum nach Tacitus ", WS, 74, 1961, p. 113-125; J.-L. Voisin, "Éthique militaire et mort volontaire sous le Haut-Empire ", dans Y. Le Bohec, C. Wolff éd., Les légions de Rome sous le Haut-Empire. Actes du congrès de Lyon, 17-19 septembre 1998, Paris, 2000, p. 727-732.

137 Suet., Oth., 10, 5 ; Tac., Hist., 2, 48, 1 ; Plut., Oth., 16, 1 ; Dio, 63, 15, 1. Cf. P. Schunck, "Studien zur Darstellung des Endes von Galba, Otho und Vitellius in den Historien des Tacitus ", SO, 39, 1964, p. 38-82.

138 Suet., Oth., 12, 3: Per quae factum putem, ut mors eius minime congruens vitae maiore miraculo fuerit; 5 : Denique magna pars hominum incolumen grauissime detestata mortuum laudibus tulit, ut uulgo iactatum sit etiam, Galbam ab eo non tam dominandi quam rei publicae ac libertatis restituendae causa interemptum; Plut., Oth., 18, 3. Cf. H. Drexler, "Zur Geschichte Kaiser Othos bei Tacitus und Plutarch », Klio, 37, 1959, p. 153-178; Y. Shochat, "Tacitus' attitude to Otho », Latomus, 40, 1981, p. 365-377 ; L. Braun, " Galba und Otho bei Plutarch und Sueton », Hermes, 120, 1992, p. 90102 ; C. A. Perkins, «Tacitus on Otho », Latomus, 52, 1993, p. 848-855.

139 Suet., Oth., 10, 4: secretoque capto binos codicillos exaranit, ad sororem consolatorios et ad Messalinam Neronis, quam matrimonio destinarat, commendans reliquias suas et memoriam. 
dement son cadavre afin qu'il ne subît pas d'outrage de la part des troupes de Vitellius. Othon reçut donc les derniers hommages ainsi qu'un tombeau ${ }^{140}$.

Tout comme Othon,Vitellius recommanda sa mémoire et celle de ses proches au Populus Romanus avant d'abdiquer le pouvoir ${ }^{141}$. Cette requête ne fut pas respectée. En effet, pour la première fois depuis le début de l'Empire, un princeps fut jeté dans le Tibre après avoir subi de nombreux outrages. Lorsque les troupes flaviennes entrèrent dans Rome et trouvèrent Vitellius, isolé de tous, caché au Palatin, elles l'emmenèrent, tel un criminel, au carcer $^{142}$. Sur le chemin qui traversait le forum et la uia Sacra, Vitellius put voir aussi que ses statues avaient été jetées à terre. Il reçut des immondices et des insultes de la part du uulgus ${ }^{143}$. Les spectateurs se jetèrent sur lui près des Gémonies et le déchiquetèrent à l'aide d'un croc. Puis son corps fut jeté dans le Tibre ${ }^{144}$. Il ne put donc pas recevoir les derniers hommages funèbres. Sa mémoire devait disparaître faute de pouvoir être honorée: il était ainsi exclu du monde des vivants $^{145}$. Le Sénat n'eut pas à voter de senatus consultum confirmant la damnatio memoriae. La réaction violente du uulgus et des soldats flaviens suffit à faire de Vitellius un damnatus.

L'étude des pratiques de la damnatio memoriae au I ${ }^{\mathrm{er}}$ siècle apr.J.-C. à travers les œuvres historiques de Tacite et de Suétone nous a permis de dégager les différentes formes que put prendre cette décision politique visant à effacer un individu de la mémoire collective et à ne pas retenir son passage dans la vie publique romaine. Elle a également permis de réaffirmer la dimension fondatrice des règnes d'Auguste et de Tibère, puisque c'est bien à partir des premières décennies du principat que la condamnation de mémoire évolue par rapport à la forme qu'elle revêtait sous la République.

Alors que la période républicaine ne connaissait que des formes d'atteinte à la mémoire touchant presque exclusivement la sphère privée de l'individu

140 Tac., Hist., 2, 3 : Funus maturatum; ambitiosis id precibus petierat, ne amputaretur caput ludibrio futurum; 2, 49, 3-4; Suet., Oth., 11, 3: modo celans modo detegens plagam exanimatus est et celeriter, nam ita praeceperat, funeratus; Plut., Oth., 17, 8; 18, 1-2; Dio, 63, 15, $1^{2}$.

${ }^{141}$ Tac., Hist., 3, 68, 2 : retinerent tantum memoriam sui fratremque et coningem et innoxiam liberorum aetatem miserarentur.

142 Suet., Vit., 17, 1-2; Tac., Hist., 3, 84, 4-5 ; Dio, 64, 20, 2-3 - 21, 1. Le criminel a la main attachée et ne doit pas avoir la tête baissée. Cette attitude permettait aux soldats flaviens de montrer à Vitellius sa déchéance puisque ses statues étaient à terre:Tac., Hist., 3, 85, 1; Dio, 64, 21, 1. Carcer: LTUR, I, Rome, 1993, p. 236-237 (F. Coarelli).

${ }^{143}$ Suet., Vit., 17, 2: quisbusdam stercore et caeno incessentibus, aliis incendiarium et patinarium uociferantibus, parte unlgi etiam corporis uitia exprobrante.

${ }^{144}$ Suet., Vit., 17, 4: tandem apud Gemonias minutissimis ictibus excarnificatus atque confectus est; et inde unco tractus in Tiberim; Tac., Hist., 3, 85: postremo ad Gemonias, ubi corpus Flauii Sabini iacuerat, propulere; Eutr., 7, 18, 5; Aur.Vict., 8, 6; Epit., 8, 4. Cf. E. Cizek, « La mort de Vitellius dans les Vies des douze Césars de Suétone ", REA, LXXVII, 1975, p. 125-130; J. Scheid, "La mort du tyran », cit. supra, p. 177-193.

${ }^{145}$ Dig., 3, 2, 11, 3. 
condamné et ne relevant que d'une décision judiciaire, on vit apparaître dès le règne de Tibère les deux caractéristiques de ce qui allait devenir pendant toute la période impériale la procédure d'abolitio memoriae: des mesures s'appliquant dans la sphère publique et une décision du Sénat d'ordre législatif directement liée à la procédure de condamnation et non plus à un procès. Cette nouvelle forme de condamnation de la mémoire s'officialisa en même temps qu'elle touchait les membres de la famille impériale et tendit, à partir de là, à se généraliser à des particuliers.

À côté de cette forme officielle de damnatio memoriae, d'autres formes plus spontanées sont observées, qui s'inscrivent davantage dans la tradition républicaine. Elles impliquent plus directement le peuple qui peut intervenir, avec ou sans relais politique, dans le traitement de la mémoire qu'il souhaite réserver à ses dirigeants et à leurs proches, soit qu'il veuille condamner soit, au contraire, qu'il souhaite s'opposer à une condamnation. À travers le traitement de la mémoire a lieu un dialogue politique entre gouvernants et gouvernés. 
08-Hollard 20:Cahiers Glotz 28/01/10 15:07 Page 20 